\title{
La sexualidad en el centro: una lectura feminista de Historias del Kronen
}

\author{
Óscar CASADO DÍAZ \\ eraziel@hotmail.com
}

\begin{abstract}
RESUMEN
La sexualidad ocupa un lugar central en Historias del Kronen de José Ángel Mañas. Desafiando toda univocidad, ésta se presenta como una construcción social en constante cambio y sometida a negociación por los agentes sociales. Dentro de esa multifuncionalidad, destaca el valor que adquiere en las relaciones de poder, convirtiéndose en un elemento de manipulación y de dominio donde se impone lo masculino sobre lo femenino, lo heterosexual sobre lo homosexual.
\end{abstract}

Palabras clave: José Ángel Mañas, sexualidad, mujer, homosexualidad.

\begin{abstract}
Everything revolves around sexuality in Historias del Kronen by José Ángel Mañas. It challenges everything regarding to the univocal and so, it's showed as an ongoing social construction and submitted to negotiation by the social agents. Related to that multifunctionality, we must emphasize the importance that it gets when it comes to power relationships, and so it becomes a manipulation and control element where the masculine prevails over the feminine, the heterosexual over the homosexual.
\end{abstract}

Keywords: Jose Ángel Mañas, sexuality, woman, homosexuality.

La sexualidad invade todos los ámbitos de la sociedad occidental. La imprecisión del concepto unido a su polisémica carga semántica favorecen una expansión que excede sus propios límites y que le otorga una desmesurada complejidad. Más allá de ser algo dado, la sexualidad se construye en las diversas sociedades, adaptándose a las diferentes necesidades y circunstancias sociales; entendida, de este modo, se formaliza como resultado de negociaciones, luchas y actividades humanas. ${ }^{1}$ Esto nos lleva al género, el cual cumple una función organizativa y normativizadora, pues, como señala Gayle Rubin, más que expresión de diferencias naturales, al

\footnotetext{
${ }^{1}$ J. Weeks (1998), p. 30.
} 
enmascararse en el entramado social, suprime las semejanzas naturales ${ }^{2}$ de tal manera que la sexualidad, y más concretamente el sistema de género, se vuelve un instrumento por el cual se ejerce el poder que impregna las relaciones entre personas. ${ }^{3}$

Algunas novelas, dado el carácter mimético en la representación de conductas y de ambientes, se muestran especialmente propicias para la observación, pero también para analizar la construcción de la sexualidad en una amplia dimensión social. No podemos olvidar que toda creación artística, como producto cultural, es, en mayor o menor medida, dependiente del contexto sociohistórico que lo genera, aunque también de las circunstancias de la recepción que determinan su significado. ${ }^{4}$ En este sentido, la novela de José Ángel Mañas, Historias del Kronen, deslumbra desde su ficcionalidad por el carácter verosímil que imprime en sus páginas. Situada en la ciudad de Madrid, recoge con un estilo sobrio y directo el ocio juvenil. La crudeza de la narración, que no tiene reservas para evidenciar el consumo de drogas o la desmesurada atracción por la violencia, también exhibe una sexualidad explícita y desinhibida, no sólo en cuanto a las relaciones sexuales, sino en el amplio espectro de los diferentes ámbitos de la vida. De los vértices del triángulo formado por las drogas, la violencia y el sexo, es este último el que cobra una mayor importancia según avanza el relato, cruzando de manera progresiva de la periferia a su centro. ${ }^{5}$ Este desplazamiento no sólo se comprende como un recurso narrativo; antes al contrario, es determinante para analizar las conductas de los personajes y, por consiguiente, para una hermenéutica de novela.

Al igual que en el medio social del cual es reflejo, Historias del Kronen establece una intrincada red de significaciones y de símbolos que se configuran recíprocamente por medio de relaciones interpersonales y comportamientos, forma más externa de una ideología de género sobre la cual se construye la sexualidad. ${ }^{6}$ Esta representación comportamental e ideológica trasluce que no existe una concepción monolítica de la sexualidad, ni siquiera en cuanto a las agrupaciones de personajes de rasgos comunes; sino que ésta adquiere formas plurales y desiguales en la propia individualidad. La diversificación de unas prácticas sociales demasiado flexibles determina la imposibilidad de mantener una posición unitaria e inamovible en el amplio espectro que abarca lo sexual. ${ }^{7}$ El contraste existente entre lo reglado dentro del ámbito público que comprende la heterosexualidad obligatoria, por un lado, y las prácticas sexuales juveniles en el ámbito privado, por otro, acaso sea la mayor evidencia de la

${ }^{2}$ G. Rubin (1986), p. 115.

${ }^{3}$ M. Foucault (2006b), p. 165.

4 No olvidemos que la sexualidad es "la actividad humana de la cultura moderna occidental con una mayor carga significativa" (E. Kosofsky Sedgwick (1998), p. 15).

${ }^{5}$ Este movimiento focalizador de la sexualidad en la novela es similar a lo que ha ocurrido en las disciplinas humanísticas. Cfr. J. A. Nieto (2003b).

${ }^{6}$ Para la diferencia entre cultura y estructura social: cfr. C. Geerzt (2005), p. 133.

${ }^{7}$ Este espectro sólo puede entenderse en las continuas variaciones del devenir histórico: "las prácticas sexuales y su consideración social varían no sólo con las culturas, sino con el tiempo" (A. Fausto-Sterling (2006), p. 28). 
disociación entre la aceptabilidad de lo exhibido y la práctica sancionada de lo oculto. $^{8}$ En efecto, ya desde el principio es fácil observar la presión de una heterosexualidad obligatoria que gravita omnipresente en todos los ámbitos de la novela; sin embargo, también se dan oposiciones que se rebelan y la cuestionan. Frente a las parejas que orientan su relación hacia el matrimonio, también se aprecian actitudes, tanto en lo heterosexual como en lo homosexual, que se alejan de esta postura cuestionándola y desafiándola.

La presión social constante de la heterosexualidad obligatoria varía según el rango de edad, la clase social o el género; no obstante, sí se muestra homogénea en lo relativo a la uniformidad al regular la identidad de género. ${ }^{9}$ En el caso del grupo de amigos que toma el Kronen como su punto de reunión, la juventud es concebida, dentro de la significación que toma dentro del contexto social, como una etapa liminal. La inestabilidad y la inseguridad atribuida a los jóvenes es comprendida como una transición que afecta a diferentes aspectos que van de lo laboral a lo sexual. De hecho, la relación de pareja estable y monogámica cuya finalidad reside en el matrimonio se identifica con una madurez personal que apunta al abandono de lo juvenil y a una entrada en una forma de vida adulta cargada de obligaciones y responsabilidades. Las relaciones sexuales heterosexuales se imponen como necesarias, marcando una primera etapa que deriva, posteriormente, hacia una relación heterosexual monógama, la cual terminará, por último, en el matrimonio. ${ }^{10}$ Este proceso es percibido por los personajes como inevitable, asumiendo que aquellos que se niegan a aceptarlo se encuentran todavía en una primera etapa a la que seguirá, forzosamente, una vida conyugal: "Y tú también te casarás algún día. Eso les pasa a todos" ${ }^{11}$ El noviazgo formalizado como paso previo al abandono de unas costumbres sexuales disolutas se establece como un futuro más o menos cercano para quienes que se resisten a aceptar las imposiciones normativas de género. ${ }^{12}$ En el interior de esta concepción del proceso vital, la homosexualidad es inconcebible para los miembros del grupo, interpretando las actitudes que escapan de la imposición heterosexual como anomalías que, sin embargo, se encubren bajo un velo de eufemismos y silencios, tal como demuestran las actitudes que despierta la artificiosa abstinencia misógina de Roberto.

El caso de Carlos también escapa a la trayectoria vital impuesta por la heterosexualidad obligatoria. Su resistencia a cualquier tipo de compromiso que

8 "Lo propio de las sociedades modernas no es que hayan obligado al sexo a permanecer en la sombra, sino que se hayan volcado a hablar del sexo siempre, haciéndolo valer, poniéndolo de relieve como el secreto [sic.]" (M. Foucault (2006a), p. 36)

${ }^{9}$ Cfr. J. Butler (2007), p. 96.

${ }^{10}$ Para comparar etapas y estados liminales en la construcción de la masculinidad con otras sociedades: cfr. Deniz Kandiyoti (1994); E. Badinter (1993), pp. 94 y ss.

${ }^{11}$ J. Á. Mañas (1994), p. 59.

12 Interesante contrastar las similitudes de esta etapa liminal asociada a la vida nocturna madrileña con la que vivían los jóvenes burgueses en la bohemia: cfr. E. Kosofsky Sedgwick (1998), p. 254. 
limite su desmedido egotismo es interpretada por el resto de los personajes como una señal inequívoca de inmadurez. Así se lo hace saber Nuria: “¿Y tú? ¿Tienes novia?... No, qué va, todavía no... Tendrás que crecer algún día, Carlos. No puedes seguir siempre así"; ${ }^{13}$ y también Amalia, que se expresa de manera similar. ${ }^{14}$ Sin embargo, su rebeldía ante la monogamia tiene un origen mucho más complejo que la maduración personal, pues concierne a cómo concibe las relaciones entre géneros. La perspectiva sexista que adopta Carlos, como la mayoría de los varones de la novela, es determinante para la construcción de una identidad sexual creada por oposición a lo femenino y, a su vez, a lo homosexual. ${ }^{15}$ Esto queda reflejado en la agresividad sexista de su comportamiento, pero también de un lenguaje repleto de connotaciones sexuales que tiende a la reificación de las personas e imposibilita la empatía con ellas. ${ }^{16}$

A pesar de la trayectoria vital dominada por la heterosexualidad obligatoria, las relaciones sexuales entre jóvenes en la novela son concebidas al margen de la procreación y, en muchos casos, al margen de la relación sentimental. El acto sexual en sus múltiples variantes se contempla como prioritario dentro del espacio de ocio, junto al consumo de drogas o a comportamientos o acciones que provoquen emociones fuertes, que impliquen riesgo y peligro. ${ }^{17}$ La búsqueda desmesurada del placer y de la autosatisfacción se condensa en el lema "muere joven y deja un cadáver bonito". ${ }^{18}$ Este manido carpe diem de exaltación hedonista, despreocupado y ciego

${ }^{13}$ J. Á. Mañas (1994), p. 99.

${ }^{14}$ Ibíd., p. 170.

${ }^{15}$ Recordamos la conocida sentencia de R. Stoller que determina la construcción de la masculinidad: "La primera obligación para un hombre es la de no ser una mujer" (E. Badinter (1993), p. 70); la cual se complementa con: "Para ciertas personas, el simple hecho de no ser homosexual constituye la mejor prueba de la masculinidad" (E. Badinter (1993), pp. 123-124).

${ }^{16}$ De manera constante, las mujeres son reificadas lingüísticamente por medio del término "cerda". No ocurre así con su madre o con su hermana, las cuales, al primar la relación de parentesco sobre el deseo sexual, serán denostadas por los atributos: "vieja" y "gorda" respectivamente. "Un lenguaje de abuso sexual ("chica fácil" y "golfa") funciona para mantener en orden a las muchachas y para reforzar las distinciones convencionales entre las que lo hacen y las que no" (J. Weeks (1998), p. 34); "El lenguaje adquiere el poder de producir lo socialmente real a través de los actos locutorios de los sujetos hablantes" (J. Butler (2007), p. 231). Para un análisis morfoléxico del sociolecto de la novela: cfr. P. Capanaga (1996); I. Santos Gargallo (1997).

${ }^{17}$ No es momento aquí para tratar las relaciones estructurales entre ocio y poder, aunque sí lo haremos indirectamente al tratar las relaciones entre sexualidad y poder; de ahí que sólo apuntemos de manera episódica las visionarias palabras de Hebert Marcuse: "Sólo en el último nivel de la civilización industrial, cuando el crecimiento de la productividad amenaza con desbordar los límites impuestos por la dominación represiva, la técnica de la manipulación en masa ha tenido que desarrollar una industria de la diversión que controla directamente el tiempo de ocio, o el estado ha tomado la tarea de reforzar tales controles" (H. Marcuse (1971), p. 56).

${ }^{18}$ J. Á. Mañas (1994), p. 43. 
para el futuro, encuentra su versión más radical en Carlos. Su egotismo se manifiesta a través de lo corporal, pareciendo encontrar su identidad por medio de lo sensorial, incluso de lo cenestésico; son obstante, por otro lado, existe una evasión constante de todo aquello que resulta doloroso o, sencillamente, molesto. De ahí la superficialidad que domina las relaciones humanas que mantiene Carlos, pero, en general, todas aquellas que se dan dentro del grupo que frecuenta: "Con ellos no se habla nunca. Cuando salimos, contamos chistes, decimos tonterías, burradas, hablamos de tías eso siempre - pero nunca hablamos de nosotros. Llevamos toda la puta vida juntos, desde el colegio, y es como si no nos conociéramos en absoluto. No nos contamos nunca nada. No comunicamos". ${ }^{19}$ La incomunicación, la imposibilidad de manifestar los sentimientos, de expresar vivencias personales, de salir de las conversaciones tópicas impuestas por el grupo de amigos, está regida por el acuerdo tácito que todos respetan por miedo a la sanción de los demás, especialmente de Carlos; de tal manera que la permanencia en el grupo exige determinados comportamientos y actitudes respecto a cómo divertirse, a lo que puede y no puede ser dicho o a cómo manifestar la sexualidad. ${ }^{20}$

En este sentido, la sexualidad se desliga completamente de la moral tradicional burguesa heredada del s. XIX que la vincula al espacio conyugal y a la función reproductiva. ${ }^{21}$ Los personajes de la novela consideran el erotismo como algo independiente de la procreación, del mismo modo del matrimonio. El sentimiento amoroso tampoco es un requisito indispensable para iniciar una relación sexual. Es el deseo, movido por la atracción y la búsqueda de placer, lo prioritario, en la mayoría de los casos, en el contacto sexual, hasta el punto de determinarlo. ${ }^{22}$ Una concepción prioritariamente hedonista de la sexualidad no tiene que ser destructiva ni amoral; de hecho, en la novela, observamos cómo opera de diferentes maneras según los personajes, los cuales proyectan su ideología y su personalidad en la manera de vivir y de comprender la sexualidad. Si bien la búsqueda del placer predomina en las relaciones sexuales que mantienen Carlos y Amalia a lo largo de la novela, en ambos casos no se revela de la misma manera. Si bien ambos consuman su atracción sexual, el egoísmo de Carlos, su tendencia a la dominación y a la violencia, su menosprecio por los demás, su incapacidad para la empatía y su solipsismo comunicativo se oponen radicalmente a la entrega de una Amalia cuyo placer se realiza a través de una

${ }^{19}$ Ibíd., p. 233.

${ }^{20}$ Desde la visión estereotipada de la sociedad occidental: "La identidad masculina se asocia al hecho de poseer, tomar, penetrar, dominar y afirmarse, usando la fuerza si es necesario. La identidad femenina, por su parte, se identifica con el ser poseído, dócil, pasivo, dado al sometimiento" (E. Badinter (1993), p. 123). Cfr. M. Villaseñor-Farías, J. D. Castañeda-Torres (2003), p. 45.

${ }^{21}$ Cfr. M. Foucault (2006a), pp. 114 y ss.

22 "Ciertamente, se puede conceder que el deseo está radicalmente condicionado sin afirmar que está radicalmente determinado, y se puede reconocer que hay estructuras que posibilitan el deseo sin afirmar que estas estructuras son eternas y recalcitrantes, insensibles a la reiterada repetición y al desplazamiento" (J. Butler (2008), p. 76). 
realización mutua. Así, aun basándose en un mismo propósito, la sexualidad de Carlos (al igual que la mayoría de sus actos) conduce al sufrimiento y a la reificación de los demás, no así la de Amalia, que tiende a la satisfacción y a la realización, a la vez que refuerza los vínculos afectivos. Esto desacredita interpretaciones unívocas del la práctica sexual, que se basan en principios generales, especialmente aquellos basados en rígidos imperativos y presupuestos morales, que parten de prejuicios y olvidan contexto para el análisis.

Otro aspecto destacado es la liberación de lo sexual, que desestabiliza el sistema establecido de géneros y genera una nueva normatividad que afecta directamente a cómo éstos se construyen; lo cual resulta evidente en el caso de los roles femeninos al ser contemplados desde una perspectiva generacional. En efecto, en un extremo encontramos a Sara, la anciana que vive con el abuelo. Fue acogida por éste durante la guerra Civil, y desde entonces ha estado a su servicio. Sara se ocupa de las labores domésticas: "Aquí la ves con sus casi noventa años y todavía hace la limpieza, la compra y lo que haga falta". ${ }^{24}$ Esta esclava doméstica, sin remuneración, parece pagar con un servicio vitalicio la deuda contraída por su acogida. No existe ninguna referencia a su sexualidad, pero es fácil imaginar que su servidumbre impone una abstinencia sexual determinada por la estricta reglamentación patriarcal en la que fue educada. $^{25}$

El mismo abuelo de Carlos se convierte en un testimonio vivo de la transformación cronológica que ha sufrido la mujer a lo largo del siglo pasado. Sus quejas contra la desestructuración familiar, provocada en gran medida por la entrada de la mujer casada en el mundo laboral, se ejemplifican en la generación siguiente, sus hijas, a las que reprocha que trabajen o no coman en casa. ${ }^{26} \mathrm{La}$ diatriba apocalíptica del anciano sobre "el final de la familia tradicional" nos muestra el verdadero precio que esconde la estabilidad familiar: la servidumbre y el sacrificio de

${ }^{23}$ Esa multifuncionalidad de la sexualidad remite inevitablemente a la interpretaciones que se proyectan sobre ella: "En lugar de considerar la sexualidad como un todo unificado, debemos reconocer que hay diversas formas de sexualidad: de hecho, hay muchas sexualidades. Hay sexualidades de clase y sexualidades específicas de género, hay sexualidades raciales y sexualidades de lucha y elección. La "invención de la sexualidad" [...] es un proceso continuo que simultáneamente actúa sobre nosotros y del que somos actores, objetos del cambio y sujetos de esos cambios" (J. Weeks (1988), p. 46). La sexualidad no es un fenómeno aislado, sino que, a la manera de la descripción densa geertziana, ha de ser comprendida en su contexto cultural (Cfr. C. Geertz (2005)). La hermenéutica de la sexualidad en su multiplicidad de sentidos encuentra su correlato teórico literario en el concepto de apertura, en el cual, según las perspectivas adoptadas en las interpretaciones, los diversos sentidos resultantes no se anulan, sino que se superponen: Cfr. U. Eco (1962).

${ }^{24}$ J. Á. Mañas (1994), p. 83.

${ }^{25}$ Cfr. E. Sanchis (2005).

${ }^{26}$ J. Á. Mañas (1994), p. 85. "El trabajo para esta generación de mujeres, constituye, en la mayoría de los casos, no sólo una forma de independencia económica, sino también un instrumento de la identidad propia" (P. Folguera (2008), p. 453) 
una mujer inmersa en una normatividad que le imponía ser "el núcleo y el alma de la familia". ${ }^{27}$

Si bien la siguiente generación de mujeres contrasta con la anterior a la que pertenecen Sara y el abuelo, más aún lo hará la que se corresponde con sus nietas. La independencia económica, que tan incomprensible resulta para el abuelo por apartar a la mujer del "femenino" ámbito doméstico, es determinante para el logro de la independencia y, al mismo tiempo, de la libertad sexual. ${ }^{28}$ Las mujeres más jóvenes de la novela, a pesar de su diversidad, muestran posiciones que debilitan al patriarcado. A pesar de las dificultades sexistas, encontramos una mayor libertad en cuanto a las opciones de vida, y esto se observa en la diversificación de los roles de género disponibles. Se trata de mujeres que tienen acceso a una educación superior, que conducen, que administran su dinero, que rigen sus propios negocios, que toman la iniciativa en las relaciones sexuales; exhiben, de este modo, una independencia impensable en generaciones anteriores. ${ }^{29}$ Esta paridad genérica en cuanto a las posibilidades, si bien no es absoluta en la práctica, sí muestra una ruptura con el estereotipo femenino, lo cual resulta especialmente visible en el ámbito sexual, donde se muestran activas y decididas; pero también con comportamientos que comprometen los límites normativos y conductuales esperados y asignados socialmente a su género. Estas mujeres rompen el silencio que cubre pudorosamente lo sexual haciendo visible su deseo: Rebeca, madre soltera, llama a Carlos para comunicarle que "ya puedes venirte para mi casa porque estoy buenísima y tengo unas ganas enormes de tocarte la polla", ${ }^{30}$ se muestran atrevidas al atentar contra las normas que impone el patriarcado: como la hermana de Carlos, que mete a su novio por la ventana de noche mientras sus padres duermen ${ }^{31}$ o adoptan comportamientos atribuidos al género masculino: Nuria envía un ramo de flores al chico que la ha rechazado por haberla tratado con sensibilidad y respeto. Son mujeres que saben imponer su voluntad, que rechazan a los hombres que las han utilizado, que reafirman su dignidad, que valoran las parejas que respetan su libertad e, incluso, que descubren

${ }^{27}$ Ibíd., p. 85. Inherente al rol de mujer casada dentro de la familia, habría que añadir el de madre. Cfr. L. Otero Quintas (2001); C. Clément y J. Kristeva (2000), pp. 76 y ss.; S. Beauvoir (2001), vol II, pp. 183 y ss., y 275 y ss.

${ }^{28}$ De las dos imperiosas demandas que observa Virginia Woolf para la mujer, el voto y el dinero, la segunda le parece la más importante. "De modo que cuando os pido que ganéis dinero y tengáis una habitación propia, os pido que viváis en presencia de la realidad, que llevéis una vida, al parecer, estimulante, os sea o no os sea posible comunicarla" (V. Woolf (2005), p. 182).

${ }^{29}$ No es necesario recordar la legislación que, antes de 1978, obligaba a la mujer a obtener un permiso del marido para trabajar o a cederle sus ahorros con el matrimonio. La potestad marital "autorizaba al marido a corregir a la esposa y obligaba a ésta a obedecerle, estableciendo así un plano de prevalencia [sic.] masculina que le servía de justificación" (Nuria Valera (2008), p. 195). Cfr. M. T. Gallego Méndez (1983); A. I. Benito y E. M. Martínez (2000); S. Tavera García (2008).

\footnotetext{
${ }^{30}$ J. Á. Mañas (1994), p. 28.

${ }^{31}$ Ibíd., p. 44.
} 
su superioridad ante los hombres que las pretenden. Aunque esto no ocurre en todos los casos ni de la misma manera, así ocurre con Rebeca, cuando Carlos la aborda tras haberla despreciado anteriormente; o con la dueña del Vía Láctea, quien le rechaza con prepotencia: "Anda, ábrete, mocoso, y deja de hacer el ridículo... Quiere hablar conmigo, ja, ja, qué gracioso", ${ }^{32}$ o con Amalia después de que Carlos la presionase para que lo satisficiera sexualmente. ${ }^{33}$

Mujeres jóvenes como Nuria o Amalia presentan cierta ambigüedad en cuanto a su autonomía en lo referente a las relaciones de pareja. La relación anterior de Nuria era obsesiva: "No soy tan dependiente de él como lo era de Luis, no tengo necesidad de estar pegada a él las veinticuatro horas del día"; ${ }^{34}$ ella mantenía la relación a pesar de las "putadas" que le hacía Luis. Después de esa relación permanece un año sin salir con nadie, lo cual le sirve para replantearse su concepción de cómo debe actuar y cómo debe ser una pareja; sin embargo, pensar también en ella y no sólo en las necesidades de su pareja le hace sentirse algo culpable: "me hacía falta aprender a ser un poco egoísta". ${ }^{35}$ De hecho, aunque su nuevo novio la respeta, y ella tiene "confianza y libertad", la dependencia sigue presente, hasta el punto de supeditar su futuro al futuro de su novio: "Quiere sacarlas [las oposiciones] en septiembre. Si las gana, es posible que se vaya a trabajar a Bruselas y yo me iría a vivir con él" ${ }^{36} \mathrm{La}$ normatividad que impone la heterosexualidad obligatoria por medio del proceso de socialización domina el pensamiento de Nuria. El matrimonio es para ella una etapa ineludible en la vida; etapa que como ya hemos señalado, está determinada por la madurez y la asunción de responsabilidades. Esto se hace especialmente patente cuando le insiste a Carlos en que debe "echarse novia" para empezar a madurar.

Algo similar ocurre con Amalia. Al igual que otras mujeres jóvenes de la obra, rompe con los estereotipos femeninos. Activa y decidida, trabaja para marcharse de casa de sus padres ${ }^{37}$ muestra un desinterés total hacia la cocina ${ }^{38}$ se ocupa de la rehabilitación de su novio toxicómano, ${ }^{39}$ o se pelea para defender a sus hermanos. ${ }^{40}$ Amalia se dedica a trabajar con deficientes mentales, haciendo que se comuniquen y salgan de su aislamiento. ${ }^{41} \mathrm{Su}$ preocupación por los demás y la empatía que siente hacia los que sufren contrasta con el egocentrismo y el individualismo de Carlos, el cual se evade de la realidad continuamente, huyendo de toda situación problemática. Amalia se enfrenta a las dificultades, especialmente las que se le plantean en la relación con su antiguo novio, asistiéndole en sus crisis causadas por las drogas,

\footnotetext{
${ }^{32}$ Ibíd., p. 179.

${ }^{33}$ Ibíd., pp. 198 y 211.

${ }^{34}$ Ibíd., p. 145.

${ }^{35}$ Ibíd., p. 145.

${ }^{36}$ Ibíd., p. 145.

${ }^{37}$ Ibíd., p. 70.

${ }^{38}$ Ibíd., p. 127.

${ }^{39}$ Ibíd., p. 72.

${ }^{40}$ Ibíd., p. 128.

${ }^{41}$ Ibíd., p. 169.
} 
incluso en situaciones límite de agresión o de intento de suicidio. El comportamiento de Amalia en la relación de pareja no está exento de cierta ambigüedad en su interpretación. A pesar de la disposición que muestra para solventar los problemas, o la resolución y la independencia que la caracterizan, aguanta las continuas vejaciones que sufre en una relación de pareja mantenida durante cinco años con un novio toxicómano, fuertemente afectado, tanto física como mentalmente, por las drogas. La empatía y la fidelidad que siente hacia él la obligan a mantenerse a su lado para ayudarlo; pero es difícil determinar hasta qué punto influye el peso de la normatividad que exige determinadas actitudes a la mujer en la relación de pareja. Este peso normativo se pone de manifiesto en la situación que se produce con Carlos en su casa. Éste intenta forzarla directa e indirectamente a mantener una relación sexual, a pesar de que ella se resiste y le hace explícita su negativa. Sin embargo, Amalia acabará cediendo, aunque muestra ostensiblemente no tener ningún interés en ello. De hecho, al ceder, señala: "Te lo voy a hacer, por pesado, pero no lo hago a gusto". ${ }^{42}$ El acto en sí se limita a una masturbación rápida, sin ninguna implicación emocional por su parte: "Ella se resiste y rechaza mis lengüetazos mientras continúa masturbándome mecánicamente" ${ }^{43}$ Resulta sorprendente que ella, que se muestra dominante y activa en la relación entre ambos, incluso en las relaciones sexuales, acabe cediendo en este último encuentro. Amalia no concibe una sexualidad dependiente del amor ni de una relación estable, sino por el deseo y la atracción. Por esto, unido a su carácter decidido y enérgico y a su forma de enfrentar los problemas, no deja de extrañar que Carlos acabe imponiendo su voluntad; más aún cuando Amalia, en ese momento, ya es conocedora de la personalidad oculta y camaleónica de Carlos: "Lo que más me duele es que me has engañado, Carlos. Me has hecho creer que eras como no eres"; 44 "Ja, cómo miente el cabrón. Tú no sabes querer". 45

Aunque existe una discordancia con ciertos estereotipos, lo cierto es que en la obra se presentan modelos de feminidad a través de roles femeninos marcados: madre, abuela, criada, hermana, amiga; lo cual no significa que desde esa perspectiva no se cuestione una feminidad tradicional estereotipada y se rompa con determinados moldes de género. ${ }^{46}$ Esta ruptura puede no ser total, pero sí se produce en varios aspectos según los personajes, como lo demuestran los casos de Amalia, Rebeca, o la dueña del Vía Láctea. La novela refleja, de esta manera, una situación de transformación social en lo referente a lo genérico, que tiene bastante de liminal. Sin embargo, esto no puede entenderse como un mero cambio de un estado de la situación de la mujer y de su función a otro estado distinto, ya que los procesos sociales están en continuo movimiento; como bien demuestra el caso que nos ocupa.
${ }^{42}$ Ibíd., p. 172.
${ }^{43}$ Ibíd., p. 172.
${ }^{44}$ Ibíd., p. 171.
${ }^{45}$ Ibíd., p. 172.
${ }^{46}$ Cfr. J. Fernández Sánchez (1998); P. Nieva de la Paz (2009). 
Diferenciándose de la feminidad, en nuestra sociedad, la identidad masculina parece construirse a través de la oposición con lo femenino. ${ }^{47}$ Para los varones de la novela, especialmente para el protagonista, ser hombre es no ser mujer y, más específicamente, no ser homosexual. Esta construcción de la masculinidad reafirma las posiciones dentro del grupo de amigos, a la vez que sanciona cualquier comportamiento que rompa la normatividad exigida por la heterosexualidad obligatoria. Tanto el lenguaje como los comportamientos están orientados a evitar cualquier cuestionamiento de la virilidad entre varones. ${ }^{48}$ La mayor libertad sexual obtenida por las mujeres contrasta con posturas homófobas y machistas que son utilizadas para reforzar la identidad masculina. Resulta especialmente significativa la conversación en el Kronen, cuando alguien bromea al plantear que podrían ir a Ámsterdam, prostituir a las novias y así conseguir dinero de ellas para drogas. Celia, la novia de Miguel contesta: "Y os podríamos prostituir nosotras también, que hay mucho marica por todos lados". ${ }^{49}$ La reacción del novio es inmediata: "Espera, espera. Tengamos las cosas bien claras, Celia. Tú eres mi novia y yo meto, no me importa dónde, pero no me dejo meter. A mí la mierda no me la busca nadie" ${ }^{50} \mathrm{La}$ metáfora cargada de ironía con que responde Celia resta legitimad al discurso homófono, ya que pone en evidencia cómo Miguel está construyendo su identidad sexual: "Mirad qué toro es mi novio". ${ }^{51}$ Este rechazo a los homosexuales varones, utilizado como una reafirmación de lo masculino, es más explícito que el machismo y se da con mayor violencia. Sin embargo, a pesar de la autoafirmación constante de la identidad masculina a través de la exhibición homofóbica, no existen límites absolutos para la homosexualidad. El sexo anal no es determinante para Miguel, que en el comentario anterior parece centrarse en quién es el agente de la penetración, y no en la parte del cuerpo penetrada. La misoginia exacerbada de Roberto y su ausencia total de interés sexual hacia las mujeres se observa dentro del grupo como algo extraño; no así como un rasgo homosexual. Es significativo que ante la propuesta de Roberto de buscar unos travestíes para que les hagan una felación, alguien indeterminado, aunque probablemente Carlos, responda: "Yo, tronco, paso de que me toque el rabo un tío, eso os lo dejo bien claro". 52 Sin embargo, unas noches después, Roberto consigue convencer a Carlos para que un travestí le realice una felación; y cuando Roberto le pregunta si le ha gustado, la respuesta de Carlos es:

${ }^{47}$ Vid. nota 13.

48 A la vez que refuerza la pertenencia al grupo (evidentemente homofóbico), "la homofobia refuerza en los hombres su frágil heterosexualidad. Es pues un mecanismo de defensa psíquica, una estrategia destinada a evitar el reconocimiento de una parte inaceptable de sí mismos" (E. Badinter (1993), p. 146). Cfr. M. Foucault (2006a), p. 107; E. VargasTrujillo (2003); C. Colina (2009).

\footnotetext{
${ }^{49}$ J. Á. Mañas (1994), p. 58.

${ }^{50}$ Ibíd., p. 58.

${ }^{51}$ Ibíd., p. 58 .

${ }^{52}$ Ibíd., p. 24.
} 
"No ha estado mal". 53 La diferencia entre ambas situaciones es que esta segunda vez los dos se encuentran solos en el coche, a diferencia de la primera, donde están acompañados de Roberto y Pedro. Esto demuestra cómo la presión social, concretada en el grupo, determina posiciones ideológicas sobre la sexualidad que, en cierta medida, se ven desmentidas por la práctica privada. Los abrazos de Carlos o Roberto en el concierto, el beso que aquél le da en la boca son manifestaciones que no se consideran homosexuales para Carlos; ${ }^{54}$ algo similar ocurre con la masturbación recíproca en la casa de Fierro, que Carlos ve como algo "normal" por ser "colegas"; $\mathrm{y}$, sin embargo, inmediatamente rechaza el beso en la boca de Roberto: "Que no, que paso mucho de besarte en la boca. Eso es de julandrones". 55

También resulta significativo el cuestionamiento de los miembros que forman el grupo de amigos, especialmente Carlos, sobre la identidad sexual de Fierro. Se trata de la persona peor valorada; al ser diabético, nunca prueba el alcohol, a pesar de que el ocio del grupo dependa en gran medida de ello. Aunque nadie puede confirmarlo con seguridad, se le considera homosexual: "él era diferente, era femenino" 56 Los comentarios de Roberto sobre determinados comportamientos de Fierro indican que éste obtiene placer en situaciones provocadas de riesgo o dolor; por lo que todos le consideran masoquista. ${ }^{57}$ Esto es fácilmente extrapolado al ámbito sexual. Carlos le reprocha su debilidad continuamente y lo ataca con violencia utilizando la sexualidad. Sus ataques cuestionan su virilidad e inciden en su atribuida identidad masoquista y homosexual. No obstante, cuando se dirigen a la fiesta de cumpleaños, Carlos arremete contra Fierro, para preguntar después si tiene novio (nótese el masculino); ante la respuesta omitida en el texto, Carlos añade: “Ah, sí, es verdad que se dejó hacer una mamada por una puta con vosotros en un coche, ¿no, Roberto? Pero eso no quiere decir nada". 58 De hecho, Carlos señala que "no me molestaría que me hiciera una mamada un tío, y no soy maricón”. ${ }^{9}$ Incluso pone en duda la situación: “¿Estáis seguros de que no os la mamó él a vosotros?". 60

Todo esto indica que la homosexualidad en la novela está determinada por el acto sexual, sino por los agentes que lo realizan y la situación contextual que determina la interpretación de la identidad sexual. De ahí que Fierro sea cuestionado y no Roberto; que ciertos comportamientos sexuales de Carlos (besos en la boca a Roberto, masturbaciones entre varones, comportamientos homosexuales agresivos hacia Fierro) se interpreten como juegos o bromas; que sólo por su profesión o su forma de hablar o de vestir Carlos considere "julandrón" al peluquero que le atiende sin

${ }^{53}$ Ibíd., p. 119.

${ }^{54}$ Ibíd., p. 107.

55 Ibíd., p. 220-221. Para un análisis intercultural de las ambigüedades y paradojas que plantea la masculinidad en relación con la homosexualidad: cfr. D. Kandiyoti (1994).

${ }_{56}$ J. Á. Mañas (1994), p 235.

${ }^{57}$ Ibíd., p 235.

${ }^{58}$ Ibíd., p 216.

${ }^{59}$ Ibíd., p 216.

${ }^{60}$ Ibíd., p 216. 
conocer sus hábitos sexuales ${ }^{61}$ o que la heterosexualidad de Carlos sea puesta en duda por Rebeca al no haber ido a su casa a tener relaciones sexuales con ella. Todo esto manifiesta la liminalidad e inestabilidad de unos géneros que se transforman, los cuales son reinterpretados continuamente en su construcción preformativa. ${ }^{62}$

Esta perspectiva conduce, de manera inevitable, a una interpretación plural de la sexualidad en Historias del Kronen, a la vez que afecta directamente a relaciones interpersonales; éstas están impregnadas de aspectos políticos, que se muestran determinantes en la hermenéutica de la novela. Lo sexual, si bien está ligado al placer, al ocio o a la construcción del género entre otros muchos aspectos, también se vincula al poder que se ejerce sobre los demás. En este sentido, la sexualidad se convierte en un instrumento de control y manipulación, especialmente visible en el caso de Carlos, al concebir la vida comprendiéndola desde la dicotomía de la fortaleza y la debilidad. Al huir de todo lo que le hace débil, se aparta de aspectos emotivos, en primer lugar, pero también de cualquier manifestación de dolor o sufrimiento. Esto está unido a su egocentrismo e individualismo radical, y a una constante búsqueda del placer inmediato. Carlos concibe las relaciones interpersonales como un juego de dominación, y hay factores que determinan las posiciones de tal dominación: "Son los viejos lo que lo tienen todo: la guita y el poder. Ni siquiera nos han dejado la rebeldía: ya la agotaron toda los putos marxistas y los putos jipis de su época". ${ }^{63}$ Es evidente que el factor económico o el estatus social afectan a la situación en la escala de poder; pero no menos importante resulta el factor sexual y genérico. Ya hemos señalado como la normatividad que se impone desde la heterosexualidad obligatoria sanciona a quienes la desafían o se apartan de sus presupuestos naturalizados bajo la falacia de la normalidad. Esto, aunque matizado según el contexto individual, se observa principalmente en los roles determinados por el sexo de los agentes sociales, mucho más por sus posiciones de género. La heterosexualidad obligatoria tan vinculada al patriarcado prima a los varones, en menor medida a las mujeres y castiga a las personas que se sitúan en posiciones liminales o transgresoras. A su vez, este eje se cruza con otro que gratifica de manera gradual el tipo de relaciones sexuales, encontrándose en el punto más alto las prácticas heterosexuales, y, en el más bajo, las parafilias, pasando por una gama más o menos extensa de prácticas. ${ }^{64}$

La sexualidad como instrumento de poder se hace especialmente visible en el lenguaje. El sexismo que impregna expresiones, donde atributos sexuales masculinos y femeninos actúan con valor metafórico o metonímico, es utilizado para dominar y

${ }^{61}$ Ibíd., p. 199.

${ }^{62}$ Cfr. D. Córdoba García (2003).

${ }^{63}$ J. Á. Mañas (1994), p. 67. En esta reflexión sobre el poder, Carlos parece centrarse en lo económico, omitiendo el elemento sexual. Acaso estas palabras de Foucault la complementen: "La sexualidad aparece más bien como una vía de paso para las relaciones de poder, particularmente densa: entre hombres y mujeres, jóvenes y viejos, padres e hijos, educadores y alumnos, sacerdotes y laicos, gobierno y población" (M. Foucault (2006a), p. 109).

$$
{ }^{64} \text { Cfr. G. Rubin (1989). }
$$


controlar determinadas conductas en beneficio propio. Se trata de un lenguaje considerado socialmente masculino, impregnado de violencia explícita y sexual, que se utiliza principalmente entre varones para autoafirmar una posición y un reconocimiento; pero también para satisfacer unas expectativas que, de otro modo, implicarían la sanción y, en último término, la exclusión. Como instrumento de comunicación y de intercambio social, el lenguaje refuerza los valores establecidos en la construcción de la masculinidad al exhibir la identidad personal y sexual en el contacto con los otros; se entiende, de este modo, como la forma más externa de una ideología y una práctica sexual que, en la mayoría de sus facetas, se integran dentro del ámbito privado. Sin embargo, el lenguaje no se relaciona solo como exhibición de la sexualidad, sino que, en conjunción con ésta, se transforma en un instrumento de dominio. ${ }^{65}$ El lenguaje preformativo actúa en las personas, construyendo identidades, pero también modelando comportamientos e ideas, de tal modo que no puede obviarse su poder transformador, tanto en los agentes sociales como en la realidad contextual que éstos habitan y perciben. El lenguaje representa los valores establecidos para la masculinidad y la feminidad, y se hace patente en los diálogos de los personajes. ${ }^{66}$

¿Hasta qué punto se pone en práctica esta performatividad lingüística relacionada con el ejercicio del poder en Historias del Kronen? Si partimos de de Carlos, quien relata sus vivencias a través de una narración en primera persona caracterizada por ser concisa y directa, carente de toda preocupación retórica, observamos cómo utiliza la sexualidad a través del lenguaje para controlar a otras personas, pues reafirma su discurso de dominio en los valores imperantes en el grupo, pero también en la normatividad que impone la sociedad. Moviéndose en ambos ámbitos, Carlos conduce las situaciones a su terreno, de tal manera que obtiene provecho sin importarle los perjuicios que ocasiona a aquellos de los que se sirve. La provocación que tiene como objetivo la manipulación de la voluntad de los demás a través del cuestionamiento de su virilidad se produce de maneras diversas. Encontramos así la asociación genital masculina con el valor: “iSeguidme!, ja que no hay cojones!”, grita Carlos para incitar a los demás a que trepen por el andamio $;{ }^{67}$ frase que repetirá Carlos a Roberto para que haga el camicace con el coche y lo conduzca por una calle en dirección contraria. ${ }^{68} \mathrm{Al}$ igual que con las referencias genitales, Carlos utiliza la homosexualidad como una provocación: "Eres un DÉBIL. ERES UN MARICA [sic.]", le grita a Roberto en el episodio del coche. ${ }^{69}$ Este desafío a la virilidad da resultado, pues Carlos consigue tanto que le sigan los demás cuando trepa por el andamio como que Roberto haga el camicace en dirección contraria. La exhibición de la masculinidad se muestra como algo fundamental para los varones no sólo en las relaciones de grupo de jóvenes, sino también en las relaciones sociales y en la

\footnotetext{
${ }^{65}$ Cfr. M. Foucault (2006a), pp. 106-107.

${ }^{66}$ J. Butler (2008), pp. 242-246.

${ }^{67}$ J. Á. Mañas (1994), p. 21.

${ }^{68}$ Ibíd., p. 193.

${ }^{69}$ Ibíd., p. 194.
} 
construcción de una identidad personal, siendo el pánico homosexual un instrumento de presión y de control del que Carlos se sirve sin ningún tipo de escrúpulos. ${ }^{70}$ Junto con la sanción inicial que le permite controlar la situación, Carlos se vale de la gratificación, utilizando los mismos conceptos iniciales: “¡Roberto, te juro que eres el tío con más cojones del mundo! Espera que se lo contemos al Miguel, vas a ver cómo va a flipar". ${ }^{71}$ De esta manera alienta y refuerza las conductas y actitudes de las que, apoyado por la ideología de género predominante en la sociedad, se ha beneficiado.

El ejercicio de poder que se ejerce sobre los varones al cuestionar su sexualidad no sólo se da entre ellos; del mismo modo que Carlos lo utiliza con los demás, Rebeca, una vez que se siente engañada y rechazada, lo utiliza contra él: "Estás con otra tía... No... Entonces, ¿por qué no vienes? ¿Con quién estás ahora? ¿Estás con un tío...?". ${ }^{72}$ En esta conversación telefónica nos encontramos ante un regateo patriarcal que utiliza como arma la masculinidad hegemónica que oprime a las mujeres. ${ }^{73}$ No es el único caso, pues Rebeca vuelve a utilizar la misma técnica para provocar y ofender a Carlos cuando se encuentran en el concierto: “¿Qué?, ¿es éste tu nuevo novio?”; ${ }^{74}$ le dice refiriéndose a Roberto.

Carlos es un elemento clave en la construcción de la masculinidad dentro del grupo de amigos y sus ideas son, en cierto modo, una referencia para los demás, especialmente para Roberto. Este liderazgo lo ejerce desde su holgada posición económica, pero, al mismo tiempo, desde una hipertrofia de los valores asociados a roles masculinos, y, de manera específica, a la violencia. La ley del más fuerte impera en su concepción vital, alentando una amoralidad que valida cualquier camino para conseguir sus fines. La ponderación de los valores masculinos en sus ideas y en su comportamiento recoge el individualismo, la insensibilidad, la incomunicación y la violencia. Se torna así una persona que evita todo sufrimiento o dolor, que escapa de las situaciones comprometidas o molestas, y que es incapaz de expresar sus sentimientos porque demostrarían debilidad. El exagerado culto a la violencia se vincula a la ausencia de empatía y a la búsqueda de un placer generado en la autocomplacencia y el ejercicio de poder. Resulta evidente que en oposición a estos valores estereotipados se encuentra los asociados a los roles femeninos y a la homosexualidad masculina. El hecho de concebir el sistema de géneros como un juego de oposiciones refuerza aún más, si cabe, la subordinación femenina y a la dominación masculina. La homosexualidad de Roberto, aun conociéndola Carlos, está permitida, pues, en primer lugar, queda encubierta tras un sexismo misógino y un decoro en el comportamiento; en segundo lugar, Carlos saca provecho de ella. De

${ }^{70}$ Para el concepto de pánico homosexual: E. Kosofsky Sedgwick (1998), p. 244 y ss.

71 J. Á. Mañas (1994), p. 195.

72 Ibíd., p. 76.

${ }^{73}$ El regateo patriarcal acuñado por Deniz Kandiyoti, consiste en estrategias que utilizan las mujeres en diferentes etapas de su vida, para obtener posiciones de seguridad y mejorar sus opciones de vida desde la situación de inferioridad en las que las sitúa el patriarcado: cfr. D. Kandiyoti (1988).

${ }^{74}$ J. Á. Mañas (1994), p. 105. 
hecho, es significativo que Carlos no tenga ningún reparo en utilizar a Roberto para el placer sexual, en besarlo en la boca, en abrazarlo del cuello, en provocarlo llamándolo marica o en exaltar su masculinidad cuando se ha conseguido de él lo que quería. Carlos se sirve de la sexualidad para controlar situaciones y para materializar su desmesurado hedonismo.

Estos valores señalados se imprimen esencialmente en el ámbito sexual. De este modo, encontramos cómo la violencia, la dominación, la incomunicación y la mentira se imponen en sus relaciones sexuales. El placer sexual para Carlos y el deseo se interrelacionan con la dominación dentro de la relación sexual. Acaso su predilección por Amalia surja de que es la única mujer en su vida a la cual no puede dominar completamente, ya que ella se muestra independiente y segura en sus decisiones, y en ningún momento depende de él; en palabras de Roberto: "Es muy frío y trata fatal a todas las tías. Bueno, había una por la que se preocupaba más que por las otras, pero yo creo que era porque ella pasaba de él. Una cuestión de orgullo o algo así". ${ }^{75}$

La relación entre violencia y sexo es explícita en el caso de las películas que ve Carlos y a las que se refiere continuamente; especial atención presta a la violencia gratuita ejercida contra las mujeres. Películas como American Psycho, La naranja mecánica o Henry, retrato de un asesino ejercen en él una influencia notable y le predisponen a imitar los roles masculinos que muestran. De hecho, no deja de ser significativo que sienta una particular atracción por la escena de Henry donde uno de los personajes viola a su hermana. ${ }^{76}$ No es sólo este caso, pues la idea de la violación es repetitiva en la novela y en la personalidad obsesiva de Carlos. Su escena preferida de La naranja mecánica es la violación de la mujer del escritor ${ }^{77}$ también aparece en la canción de Los Ronaldos: "Tendría que besarte, desnudarte, pegarte y luego violarte

hasta que digas sí". ${ }^{78}$ La sombra de la violación planea en la relación sexual con Rebeca, en la penetración anal a la que ella se resiste, mientras Carlos observa en la televisión la escena de la violación de La naranja mecánica. ${ }^{79}$ El desoír la negativa de Rebeca, la brusquedad de su comportamiento y su actitud una vez terminado el coito manifiesta una crueldad que se vincula al placer personal, y que muestra su incapacidad para empatizar. En su último encuentro con Amalia, Carlos insiste, a pesar de la oposición de Amalia, hasta que ella cede. El que Amalia lo realice forzada provoca en él una mayor excitación: "este sentimiento de que lo hace contra su voluntad me excita aún más". ${ }^{80}$ Cuando Amalia se niega a acompañarle a la fiesta de Fierro, tras insultarla con términos sexuales, se hace "una paja imaginando que le doy de hostias a Amalia". ${ }^{81}$

\footnotetext{
${ }^{75}$ Ibíd., p. 235.

${ }^{76}$ Ibíd., pp. 30 y 126.

${ }^{77}$ Ibíd., p. 32.

${ }^{78}$ Ibíd., p. 140.

${ }^{79}$ Ibíd., p. 34.

${ }^{80}$ Ibíd., p. 172.

${ }^{81}$ Ibíd., p. 211.
} 
Su comportamiento degradante hacia la mujer parte de la reificación a través del lenguaje. Carlos utiliza el apelativo "cerda" con las mujeres, especialmente con aquellas que no mantiene una estrecha relación; aunque también utiliza términos como "zorra" y "puta" contra aquellas que le contrarían. A su hermana la denomina continuamente "la gorda". La valoración que Carlos realiza de las mujeres la realiza por la apariencia, pero también por los atributos externos, especialmente los que tienen cierto valor erótico: "Elena tiene una cara bonita pero ha engordado desde la última vez que la vi. Es una pena porque me dan asco las gordas"; 82 aunque, en algún caso, estas exigencias se añaden al ámbito intelectual: "Tiene un cuerpo bonito, pero es tonta del culo. Además tiene las piernas zambas". 83

Resulta sorprendente como sexo, dominación y violencia prevalece en la pornotopía masculina del grupo: "con la puta particular encima de las rodillas, atada por una correa". ${ }^{84}$ En este sentido, la sexualidad masculina aspira a una sexualidad animal exenta de toda relación personal: "Teníamos que ser como los animales y todo sería muchísimo más simple. Los perros se huelen el culo y ya está. Y si se gustan, follan, y si no, pues no, pero no se complican la vida". ${ }^{85}$ Pero el valor reflexivo de estas afirmaciones no parte de una voluntad recíproca, sino que omite las desigualdades estructurales entre géneros dentro del sistema. Las palabras anteriores de Miguel, de las que más tarde se apropiará Carlos en su forzado encuentro con Amalia, se imponen desde un deseo sexual masculino que parte de la posición dominante que le asegura el patriarcado, al mismo tiempo que deshumaniza la sexualidad para beneficio de los varones heterosexuales.

El ejemplo más evidente de la relación entre sexualidad y poder es el caso de Fierro. Fierro, por su carácter enfermizo y su debilidad, es el miembro más discordante del grupo. Su carácter diabético que le impide beber alcohol en un grupo donde su consumo está ligado a los momentos de ocio. Esas diferencias se agravan aún más por su comportamiento "afeminado", lo que le convierte en la víctima propicia para las burlas de Carlos. En el caso de Fierro, se observa claramente cómo funciona una estratificación sexual jerárquica como la expuesta por Gayle Rubin, donde en primer lugar se encuentra la heterosexualidad, fuertemente arraigada, normalizada, difundida y beneficiada socialmente, y en último lugar, las parafilias, atravesando la homosexualidad. ${ }^{86}$ Esta pirámide de las prácticas sexuales, si bien admite diferentes grados en cada uno de sus apartados, nos sitúa en una escala moral en cuya cúspide se encuentra el sexo legitimado, o lo que es lo mismo: normal, natural, saludable, sagrado. En la base, el no legitimado, calificado de anormal, antinatural, dañino, pecaminoso, "extravagante". ${ }^{87}$ Acaso fuese necesario añadir al legitimado, fuerte o poderoso; al no legitimado, débil o sometido, pues teniendo en
${ }^{82}$ Ibíd., p. 18.
${ }^{83}$ Ibíd., p. 15.
${ }^{84}$ Ibíd., p. 59.
${ }^{85}$ Ibíd., p. 59.
${ }^{86}$ Cfr. G. Rubin (1989).
${ }^{87}$ Ibíd., p. 141. 
cuenta estos factores podríamos ubicar fácilmente y en posiciones opuestas a Carlos y a Fierro. Ya hemos visto que la heterosexualidad de Carlos roza en muchos casos lo homosexual; y en ese juego límite, en esa transformatividad sexual es donde se mezclan placer, deseo, reconocimiento social y dominación. Ante la pasividad del resto del grupo, que apenas se enfrenta a él o lo amonesta, Carlos ataca a Fierro desde su concepción ideológica basada en la ley del más fuerte por medio de la sexualidad. Contemplándolo por lo que le diferencia, Carlos observa en Fierro lo contrario a lo que un "hombre" debería ser. Fierro es para él débil y enfermizo en su constitución y carácter; en lo sexual, afeminado, homosexual y masoquista. Aunque Carlos tiene sus dudas, Roberto le convence con ejemplos; primero con reminiscencias infantiles que ya apuntaban: "No sé si te acuerdas que ya en el colegio le pedía a todo el mundo que le pegara, que le pegaran, por favor...", ${ }^{88}$ después con un ejemplo inmediato: "Yo me metí en el coche y le seguí con las luces apagadas, por si le pasaba algo"; ese seguimiento acabará convirtiéndose en una persecución en la que Fierro saltará al las zarzas de la cuneta antes de ser atropellado: "Luego salió sangrando, lleno de arañazos, y me dijo que había sido cojonudo, que lo hiciera otra vez". 89 El convencimiento de que Fierro es masoquista sirve de detonante para el desenlace de la novela, situando la muerte de éste en el punto culminante de los excesos con las drogas y de la violencia, aspectos que sólo maquillan la verdadera motivación: la sexual.

Los momentos previos a la fiesta de cumpleaños de Fierro ya muestran un Carlos muy agresivo, con ataques dirigidos hacia la sexualidad "desviada" de aquél. El día antes de la fiesta, cuando se encuentran los dos en el Kronen, Carlos se ensaña con él: "El Fierro está tan amariconado como siempre"; “ ¿Te vas a poner tangas de cuero y nos vas a dar látigos?”; “زJoder, Carlos, no me toques el culo!”; “”; "Hasta mañana, Fierro. Un beso"; "Me muero por ti". ${ }^{90}$ A pesar de su comportamiento, sólo Miguel parece reprenderle una vez que Fierro se ha marchado. El regalo de cumpleaños es también motivo de escarnio para Carlos; de hecho, antes de que Roberto le confirmase el masoquismo, ya proponía regalarle a Fierro: "Un vibrador y un botecito de Popers para que lo esnife antes de correrse", regalos que inciden en la supuesta homosexualidad. ${ }^{91}$ Si bien le acabará comprando un par de discos, mantendrá comentarios continuados sobre el regalo del consolador. La imprevista ausencia de mujeres en la fiesta es utilizada por Carlos en una interpretación ofensiva contra Fierro: "[...] es un complot de Fierro que solo quiere tener pollas para que le demos todos por el culo". ${ }^{92}$ Ya en la fiesta, la agresividad lingüística centrada en lo sexual es continuada, potenciada por el consumo de drogas, que actúan como desinhibidores conductuales. Las burlas y la agresividad sexual hacia Fierro encontrarán término en su muerte: atado en una silla, es obligado a ingerir alcohol por un embudo hasta que,

\footnotetext{
${ }^{88}$ J. Á. Mañas (1994), p. 136.

${ }^{89}$ Ibíd., pp. 136-137.

${ }^{90}$ Ibíd., pp. 201-202.

${ }^{91}$ Ibíd., p. 183.

${ }^{92}$ Ibíd., p. 216.
} 
dada su diabetes, colapsa. Como no podía ser de otra manera, las referencias a la sexualidad desviada de Fierro desempeñan un papel decisivo en el asesinato: "Para que sea aún más excitante, te vamos a vendar los ojos"; "Es como Nuevesemanasymedia"; "Te encanta, $i a$ que sí? Mirad el bulto que tiene en el pantalón. Se está empalmando"; "Venga, vamos a acariciarte el paquete"; "[...] yo desabrocho el pantalón para que veamos que hombre es Fierro"; "Oh, pero ya no estás excitado, Fierro. Nos has decepcionado"; "Un poquito de coca de la bandejita en el pequeño capotito de Fierro y, op, la resurrección". ${ }^{93}$ La violencia de Carlos no terminará ahí, ya que, ante la imposibilidad de reanimar el cuerpo de Fierro, comenzará a golpearlo mientras le reprocha a él y a los demás su debilidad; también su masculinidad: “ $¡ U N A$ MIERDA DE HOMBRE! ¡MERECES QUE TE ESTAMPE LA CABEZA CONTRA EL SUELO Y QUE TE LA PISOTEE HASTA QUE MUERAS DE VERDAD!". ${ }^{4}$

En realidad, puede entenderse fácilmente cómo la violencia ejercida sobre Fierro está motivada por causas sexuales. Su debilidad se debe, en gran medida, no sólo a su constitución o su diabetes, sino a que "era diferente, era femenino"; lo cual le convierte, en palabras de Roberto, en "la víctima propicia". 95 Al participar de una sexualidad "desviada" para el grupo, también por los tácitos imperativos sociales, mucho más por ser contemplado como masoquista, su muerte, de alguna manera, incluso está justificada: "En el fondo no se le puede culpar a Carlos. Fierro se lo buscaba. Hasta se excitó mientras le atábamos...". ${ }^{96}$ Es la heteronormatividad impositiva que sanciona, discrimina y justifica la violencia contra minorías sexuales. Sin embargo, esa heteronormatividad no sanciona al Carlos parafílico, incluso lo protege y lo ampara; porque, si bien Fierro es masoquista, más claramente Carlos es sádico. La diferencia entre ambos es que el grupo-sociedad ampara al sádico, licitita su ideología, disculpa sus actitudes, naturaliza su comportamiento y admite su sexualidad. ${ }^{97}$ Algo que no ocurre en el caso de Fierro, cuya sexualidad lo convierte, efectivamente, en la víctima. Y eso es algo que no sólo se produce en la individualidad de las relaciones interpersonales, sino que se sostiene y se protege en estructuras sociales determinadas, las cuales, en la mayoría de los casos, permanecen invisibles, ocultas por su carácter normativizado. ${ }^{98}$

${ }^{93}$ Ibíd., pp. 221-222.

${ }^{94}$ Ibíd., p. 223.

${ }^{95}$ Ibíd., p. 235.

${ }^{96}$ Ibíd., p. 235.

97 Para una interesante reflexión sobre las paradojas que observa la relación sadomasoquista: Cfr. C. Lynn (2003).

98 "El poder es tolerable sólo con la condición de enmascarar una parte importante de sí mismo. Su éxito está en proporción directa con lo que logra esconder de sus mecanismos" (M. Foucault (2006a), p. 90). "Tal vez la acción de la norma se encuentra no sólo en el ideal que postula sino también en el sentido de aberración y de anormalidad que transmite" (J. Butler (2008), p. 106). 
Todo lo expuesto en el análisis precedente conduce a contemplar Historias del Kronen como un impactante retrato de una sexualidad (sensu lato) cambiante en una sociedad también cambiante. La contextualización de la historia en un momento histórico concreto, donde tanto estereotipos como roles son variables y donde los paradigmas sexuales muestran fuertes variaciones entre generaciones, provoca que la novela sea el reflejo de una etapa liminal y, ciertamente, conflictiva. Estas transformaciones que se estaban produciendo a principios de la década de los noventa en la sexualidad y el género, las cuales habían comenzado en las décadas anteriores, no dejan de ser una concreción de transformaciones sociales más amplias, que afectan a la manera de vivir de la clase media. Las actividades en tiempo de ocio, las relaciones familiares y de pareja, el consumo de drogas o las posiciones sociales de género son muestras específicas que, a modo de un vertiginoso vórtice, acaban convergiendo en un centro donde aguarda la sexualidad. La sexualidad es la intersección, pero una intersección activa; un centro del relato que es a su vez estructurador, receptor y generador. La sexualidad, en todas sus dimensiones, parte como un elemento más dentro de la vorágine subjetiva que muestra ser la vida del protagonista; pero según avanza la narración, comienza a prevalecer hasta que al final del relato ha ocupado un puesto central. Sin embargo, en el ámbito de aplicación de la novela, al igual que en el ámbito social, sólo puede concebirse la sexualidad desde una perspectiva multifuncional. No se impone sobre ella una visión unívoca; antes al contrario, sólo puede ser concebida desde la pluralidad; una pluralidad calidoscópica en la que influyen las situaciones y características de los personajes, concebidos como agentes sociales: sexo biológico y género, pero también estatus socioeconómico, formación, etc.; afectándoles de manera desigual realidad contextual.

De entre esos ejes transversales que cruzan la sexualidad en Historias del Kronen adquiere una preeminencia notable el que se centra en el ámbito de las relaciones de poder. Es ahí donde la sexualidad se convierte en un elemento maleable, dúctil, adaptable a los propósitos de Carlos, aunque también del resto de los personajes. Esta adecuación nos muestra cómo la sexualidad se convierte en un instrumento para determinados fines; y que su valor moral y el beneficio que aporta a las relaciones interpersonales no se encuentra en sí misma, sino que está determinado por su uso. Un uso que, en el caso del protagonista, es inseparable de la dinámica de dominación y provecho propio, en notable detrimento de las personas que lo rodean. ${ }^{99}$

La novela, dado su carácter mimético y verosímil, representa la sexualidad como una construcción social, en ningún caso inamovible, que está en constante cambio, y que permanece sometida al diálogo y a la negociación tanto de instituciones como de agentes sociales. En gran medida, esto explica sus diferentes valores y usos, pero también la conflictiva relación que mantiene con el poder. Se impone así una heteronormatividad macroestructural que se concreta en la particularidad de la

99 "En las relaciones de poder la sexualidad no es el elemento más inerte, sino, más bien, uno de los que están dotados de la mayor instrumentalizad: utilizable para el mayor número de maniobras y capaz de servir de apoyo, de bisagra, a las más variadas estrategias" (M. Foucault (2006a), p. 109). 
persona, manifestándose como una presión normativa, a la par de ofrecer ciertas posibilidades, sancionadas o no, de desarrollo en cuanto a las prácticas sexuales, identidades sexuales o genéricas con los consiguientes roles asociados. De tal manera que la normatividad sexual puede ser interpretada en su vertiente restrictiva y coercitiva, por un lado; pero también en cuanto que ofrece maneras variadas y posibles de vivir en sociedad. Historias del Kronen redunda precisamente en eso, en el hecho de que no existe un sentido unívoco ni una función social unívoca ni una práctica unívoca para la sexualidad; sino que la sexualidad, en su inestabilidad, desafía una imposición social uniforme, donde, a pesar de la generalización normativa, cada individuo tiene la posibilidad de idearla y vivirla de manera distinta. Esta potencialidad es el germen de su carácter transformador, lo cual la convierte en un desafío a lo establecido; también es el germen de su carácter revolucionario, dadas las múltiples relaciones que mantiene con todos los ámbitos del entramado social.

El pesimismo existencial que rezuma Historias del Kronen, especialmente en su parte final, no debe impedirnos distinguir, más allá de la critica descarnada, la necesidad de una transformación social donde la sexualidad, por su valor político, adquiera una importancia primordial. ${ }^{100}$ En palabras de Gayle Rubin: "Es momento ya de reconocer las dimensiones políticas de la vida erótica". ${ }^{101}$

\section{OBRAS CITADAS}

BADINTER, Elisabeth: XY. La identidad masculina, Madrid, Alianza, 1993.

BEAUVOIR, Simone de: El segundo sexo, 2 vols., Madrid, Cátedra, 2001.

Benito de los Mozos, Ana I.: y Martínez Gallego, Eva María, "Mujer, ¿sujeto u objeto de derecho?", en LÓPEZ DE LA VIEJA, Maria Teresa (ed.): Feminismo: del pasado al presente, Salamanca, Universidad de Salamanca, 2000, pp. 87-102..

BUTLER, Judith: El género en disputa, Barcelona, Paidós, 2007.

- Deshacer el género, Barcelona, Paidós, 2008.

CAPANAGA, Pilar: "La creación léxica en «Historias del Kronen»", en Atti del Convegno di Roma II: 15-16 marzo 1995. Lo spagnolo d'oggi : forme della comunicazione, Roma, Bulzoni, 1996.

${ }^{100}$ En relación con esta crítica política que encierra la obra, resulta obligatorio reproducir el comentario de Carmen de Urioste: "Con respecto a la existencia, las novelas de Mañas designan la realidad transcendente de un sector social que ha estado y está excluido del discurso social mayoritario. Al dejar sin nombre a una parte de la sociedad cuyas prácticas son consideradas negativas por un consenso basado en la tradición, se anula la veracidad de la presencia de toda una comunidad joven que busca en la música, en la ciudad, en el bar, en el sexo y en la droga las respuestas que la sociedad de consumo no ha sabido darle. La cultura punk representada en la Tetralogía Kronen, como toda cultura de resistencia, obliga a la revisión de conceptos evitados por la sociedad española de los noventa en su afán de progreso, como son paro juvenil, drogadicción, asesinato y homosexualidad" (C. de Urioste, 2004).

${ }^{101}$ G. Rubin (1989), p. 189. 
CHANCER, Lynn: "Defendiendo una dinámica básica: paradojas en el corazón del sadomasoquismo" en NIETO, José Antonio (Ed.): Antropología de la sexualidad y diversidad cultural, Madrid, Talasa, 2003.

CléMENT, Catherine, y KRISTEVA, Julia: Lo femenino y lo sagrado, Madrid, Cátedra, 2000.

COLINA, Carlos: "La homofobia: heterosexismo, masculinidad hegemónica y eclosión de la diversidad sexual", Razón y palabra, 67, 2009.

CóRDOBA GARCíA, David: "Identidad sexual y performatividad", Atenea Digital, 4, 2003.

ECO, Umberto: Opera aperta, Milán, Bompiani, 1962.

FAUSTO- STERLING, Anne: Cuerpos sexuados, Barcelona, Melusina, 2006.

FERNÁNDEZ SÁNCHEZ, Juan (Coord.): Género y sociedad, Madrid, Pirámide, 1998.

FOlguerA, Pilar: "Voces del feminismo", en MORANT, Isabel (Dir.): Historia de las mujeres en España y América Latina IV. Del siglo XX a los umbrales del XXI, Madrid, Cátedra, 2008.

FouCAUlT, Michel: Historia de la sexualidad I. La voluntad de saber, Madrid, Siglo XXI, 2006a.

FoUCAULT, Michel: Un diálogo sobre el poder y otras conversaciones, Madrid, Alianza, 2006b.

GALlEGo MÉNDEZ, María Teresa: Mujer, Falange y franquismo, Madrid, Taurus, 1983.

GEERZT, Clifford: La interpretación de las culturas, Barcelona, Gedisa, 2005.

KANDIYOTI, Deniz: "The Paradoxes of Masculinity. Some thoughts on Segregated Societies", en CORNWALl, Andrea; Lindisfarne, Nancy (Ed.): Dislocating Masculinity, Londres, Routledge, 1994, pp. 198-199.

KANDIYOTI, Deniz: "Bargaining with patriarchy", Gender and Society, 2, 3, 1988, pp. 274-290.

KosOFSKY SEDGWICK, Eve: Epistemología del armario, Barcelona, Ediciones de la Tempestad, 1998.

LÓPEZ DE LA VIEJA, Maria Teresa (ed.): Feminismo: del pasado al presente, Salamanca, Universidad de Salamanca, 2000.

MAÑAS, José Ángel: Historias del Kronen, Barcelona, Destino, 1994.

MARCUSE, Hebert: Eros y civilización, Barcelona, Seix Barral, 1971.

MoRANT, Isabel (Dir.): Historia de las mujeres en España y América Latina IV. Del siglo XX a los umbrales del XXI, Madrid, Cátedra, 2008.

NIETO, José Antonio (Ed.): Antropología de la sexualidad y diversidad cultural, Madrid, Talasa, 2003a.

— "Reflexiones en torno al resurgir de la antropología de la sexualidad", en NIETO, José Antonio (Ed.): Antropología de la sexualidad y diversidad cultural, Madrid, Talasa, 2003b.

NIEVA DE LA PAZ, Pilar: "La evolución de los roles de género en las representaciones literarias: un camino abierto hacia el cambio social", Foro hispánico, 34, 2009.

OTERO QUINTAS, Luis: He aqui la esclava del señor: de cómo la mujer fue educada para el sacrificio y la sumisión, Barcelona, Ediciones B, 2001. 
RUBIN, Gayle: "El tráfico de mujeres: notas sobre la economía política del sexo", Nueva Antropología, VIII, 030, Mexico, 1986.

- "Reflexionando sobre el sexo: notas para una teoría radical de la sexualidad", en VANCE, Carole S. (Comp.): Placer y peligro. Explorando la sexualidad femenina, Madrid, Revolución, 1989, pp. 113-190.

SANCHIS GÓMEZ, Enric: "Trabajo no remunerado y trabajo negro en España", Papers: revista de sociología, 75, 2005, pp. 85-116.

SANTOS GARGALlO, Isabel: "Algunos aspectos léxicos del lenguaje de un sector juvenil: Historias del Kronen de J.A: Mañas”, Revista de Filología Románica, 14, 1, 1997, pp. 455-474.

TÁVERA GARCÍA, Susana: "Mujeres en el discurso franquista hasta los años sesenta", en Gallego MÉnDEZ, María Teresa: Mujer, Falange y franquismo, Madrid, Taurus, 1983.

URIOSTE, Carmen de: "Cultura punk: la Tetralogía Kronen de José Ángel Mañas o el arte de hacer ruido", Ciberletras: Revista de crítica literaria y de cultura, 11, 2004.

VALERA, Nuria: Íbamos a ser reinas, Barcelona, Ediciones B, 2008.

VARGAS-TRUJILlo, Elvia, et al.: "Variables psicosociales asociadas con el grado de aceptación de la orientación sexual no heterosexual", Psicología desde el Caribe, 12, 2003, pp. 39-51.

VANCE, Carole (comp.): Placer y peligro: explorando la sexualidad femenina, Madrid, Talasa, 1989.

VILLASEÑOR-FARÍAS, Martha, y CASTAÑEDA-TORRES, Jorge D.: "Masculinidad, sexualidad, poder y violencia: análisis de significados en adolescentes", Salud pública de México, 45, extra 1, 2003, pp. 44-57.

WEEKS, Jeffrey: Sexualidad, México D. F., Paidós, 1998.

WoOLF, Virginia: Una habitación propia, Barcelona, Seix Barral, 2005. 